\title{
The inaccessibility of the outer membrane of adherent Treponema pallidum (Nichols strain) to anti-treponemal antibodies, a possible role of serum proteins
}

\author{
JJ van der Sluis, M Kant, PC Onvlee, E Stolz
}

\begin{abstract}
Fresh and aged adherent $T$ pallidum were used to study the accessibility of their outer membrane to antibodies by means of an indirect immunofluorescent technique. The integrity of the outer membrane was demonstrated by the non-reactivity with a monoclonal antibody directed against the axial filaments. Using the sera from patients with sero-positive primary and secondary syphilis no binding of IgG and IgM antibodies was observed. However, IgG and IgM antibody fractions isolated from the sera of patients with secondary syphilis, gave with the fresh fibroblast-adhering treponemes a mean of $14.5 \%$ IgG-and of $43.2 \%$ IgM positive treponemes. These means were $32.1 \%$ and $87 \cdot 3 \%$ respectively for aged treponemes. Lower percentages were observed when fibronectin adhering treponemes were used. This demonstrates the inability of the outer membrane to bind antibodies in a majority of the fresh treponemes. This is partly lost on in vitro aging.

Absence of IgG- and IgM fluorescence was also observed when sequential incubations with the antibody fractions and control sera were used. This was accompanied by the deposition of the third complement factor (C3) around the treponemes. Incubations of IgG- or IgM pre-coated adherent treponemes with heat-inactivated control sera or a C3 deficient serum did not result in the deposition of $\mathbf{C 3}$, and partially restored the detection of human antibodies. The most likely explanation for the absence of fluorescence is that antibodies become buried in an extra-cellular layer of serum proteins. The deposition of $\mathrm{C3}$ from control sera alone most probably points to the
\end{abstract}

Department of Dermato-Venereologie, Erasmus University, PO Box 1738, 3000 DR Rotterdam, 'Thé Netherlands

J J van der Sluis, M Kant, P C Onvlee, E Stolz classical pathway of complement activation and suggests that antibodies of rabbit origin constitute a part of the extracellular layer of treponemes.

One of the intriguing aspects of syphilis is that during the disease anti-treponema antibodies are produced, but these do not lead to a rapid eradication of the treponemes. Although these antibodies may modify the course of the infection, they do not provide protection in such a manner as to prevent the disease from reaching latent infection and eventually the tertiary stage in some cases. Recent investigations, using the highly sensitive Western blotting and immunoprecipitation techniques have shown that almost all polypeptide bands obtained from solubilised Treponema pallidum react with IgG and IgM antibodies from sera of patients with secondary syphilis ${ }^{1-4}$ or rabbit immune sera. ${ }^{5}$ These preparations most probably contain polypeptides that are derived from all treponemal structures. However, as discussed by Stamm and Bassford, ${ }^{6}$ the proteins that are situated on the treponemal cell surface are especially of interest for several reasons. Among them is the notion that a protective host response presumably must be targeted against antigenic determinants exposed on the cell surface of the treponemes. Surface radiolabelling of viable treponemes revealed the presence of several immunogenic polypeptides, which could be precipitated by antibodies from rabbit immune sera ${ }^{7}$ as well as sera from patients with secondary syphilis. ${ }^{8}$ One way in which the treponemes may manage to escape destruction in vivo is by covering themselves with an extra-cellular layer, which renders their outer membrane inaccessible to the antibodies. A hypothesis dealing with such a layer was formulated by Christiansen.9 Mucopolysaccharides ${ }^{9-11}$ and host serum protein $s^{1213}$ have been implicated as constituents of a -protective-cover. However, as yet, it has to be proven that the substances present on the treponemal surface act as a barrier in preventing the access of antibodies to the antigens of the outer membrane. 
In the present experiments the treponemes were attached to cultured fibroblasts or fibronectin by their spontaneous adherence to these substrates. In this manner native treponemes could be used without a fixation procedure, which is used in the FTA-ABS test and which could possibly introduce changes in the structure of the treponemes. The adherent treponemes were used as substrates in indirect immunofluorescence studies to investigate the accessibility of anti-treponemal antibodies to the treponemal surface antigens.

\section{Materials and methods}

Treponema pallidum, Nichols pathogenic strain, was maintained in New Zealand white rabbits, as described previously. ${ }^{14}$ The rabbits were killed on day 7 and day 12 after inoculation with approximately $2.5 \times 10^{7}$ treponemes per testis. Orchitis was present in all cases. Unless stated otherwise, $1.0 \mathrm{ml}$ of basal reduced medium (BRM), ${ }^{15}$ containing $20 \%$ (v/v) fetal calf serum (FCS) (Flow Laboratories, Irvine, Ayrshire, Scotland) was added per gram (wet) minced testicular tissue and treponemes were extracted by shaking during $45 \mathrm{~min}$ under an atmosphere of $95 \% \mathrm{~N} 2$ and $5 \%$ CO2. The treponemal density was adjusted to $1 \times 10^{8}$ treponemes per $\mathrm{ml}$ by addition of a treponeme-free supernatant and subsequently to $1 \times 10^{7} / \mathrm{ml}$ by dilution with fresh BRM-FCS. The treponeme-free supernatant was prepared by centrifuging a part of the original suspension at $12000 \mathrm{~g}$ for $15 \mathrm{~min}$. The treponemal suspension was divided in aliquots of $1 \mathrm{ml}$. A part was used on the same day (fresh treponemas), the other part was stored under a reduced oxygen atmosphere ${ }^{16}$ and was used the next day (aged treponemas). The motility of the aged treponemes, as determined by observing at least 100 treponemes by darkfield microscopy of wet mounts was in all cases better than $90 \%$.

Human fibroblasts of TR strain were grown to 25$50 \%$ confluency on $20 \times 20 \mathrm{~mm}$ coverslips, kept in plastic petridishes, using F10 medium supplemented with $7 \% \mathrm{FCS}$ and $7 \%$ newborn calf serum.

Human fibronectin (FN) was a generous gift from Dr H J G Brummelhuis of the Central Laboratory of The Netherlands Red Cross Blood Transfusion Services, Amsterdam, the Netherlands. It consisted of $85 \% \mathrm{FN}$, the impurities being mainly albumin and IgG. FN was attached to $20 \times 20 \mathrm{~mm}$ cover-slips by spreading $50 \mu \mathrm{l}$ of a solution containing $0.5 \mathrm{mg}$ protein per $\mathrm{ml}$ followed by air-drying for at least one hour.

Adherence of the treponemes to monolayers of fibroblasts or to layers of FN was performed by incubating the appropriate cover-slips, kept in $35 \mathrm{~mm}$ petridishes with $1.0 \mathrm{ml}$ of $T$ pallidum suspension during $2 \mathrm{~h}$ at $34^{\circ} \mathrm{C}$ under a reduced oxygen atmosphere in a dessicator. Non-adherent treponemes were removed by rinsing the cover-slips thrice in a glass beaker filled with phosphate buffered saline (PBS, $\mathrm{pH}=7 \cdot 4$ ). The adherent treponemes were used for immunofluorescence studies. They were used either without further treatment or by analogy to the FTA-ABS reaction, after fixation with acetone (monolayers of fibroblasts and FN layers) or after air-drying (FN layers). Acetone treatment was performed by incubating the rinsed cover-slips during $10 \mathrm{~min}$ in dry acetone. The cover-slips were atmospheric-air-dried for $10 \mathrm{~min}$. The cover-slips were then rinsed again in PBS and used similarly as untreated cover-slips.

Two sets of sera, one from five individual patients with seropositive primary $\left(\mathrm{SI}^{+}\right)$and the second from five secondary (SII) stage patients, were used. The criteria for these diagnoses have been published elsewhere. ${ }^{17}$ Donor sera which were negative for syphilis were used as controls. They were also used in attempts to inhibit the fluorescence by serum. The sera were stored at $-70^{\circ} \mathrm{C}$ in small aliquots and were used in 5-fold dilutions in PBS.

A C3 deficient human serum and a Clq deficient human serum were obtained from Dr B J M Zegers (University Children's Hospital, Utrecht). Defective classical as well as alternative pathway of complement activation due to the absence of $\mathrm{C} 3$ in a C3 deficient patient has been documented. ${ }^{18}$ The Clq deficient serum lacked immunochemically detectable $\mathrm{Clq}$, but some functionally active Clq was presumably present as demonstrated by a very low level of lysis of antibody coated sheep erythrocytes. The alternative pathway of complement activation in this serum was not hampered as shown by the AP 50 value which was within normal limits. This indicates the presence of the third complement component. (B J M Zegers, personal communication.)

IgG containing fractions from pooled control sera (IgG(C)) or pooled sera from patients with secondary syphilis (IgG(SII)) were prepared by ion-exchange chromatography on DEAE-Sephadex A-50 columns and eluted with a Tris- $\mathrm{HCl}$ buffer at $\mathrm{pH}=6 \cdot 5$. The 19 S-peak which was isolated from control $(\operatorname{IgM}(\mathrm{C}))$ or secondary syphilis ((IgM(SII)) sera by exclusion chromatography on Sephadex G-200 was used as an IgM enriched fraction. These serum fractions were concentrated to the initial volume of the serum from which they were derived. This was achieved using Amicon concentration cells equipped with PM 10 membranes (Amicon, Oosterhout, the Netherlands). The serum fractions (FTA-ABS titres: IgG(SII) fraction: 1:320; IgM(SII) fraction: 1:160) were used in the fluorescence assays in 10-fold dilutions.

A mouse IgM monoclonal antibody (MoAb) to the axial filaments of Nichols pathogenic treponemes (CC9) was generously supplied by $\operatorname{Dr} M$ Bailey (University of Birmingham, England).

Conjugates to human $\mathrm{C} 3$ and the $\mathrm{Fc}$ fragments of human IgG and IgM were obtained from Nordic 
(Tilburg, The Netherlands). They consisted of the IgG fraction from antisera raised in goats and labelled with fluorescein isothocyanate (FITC). The conjugate against mouse immunoglobulins was the IgG fraction from a rabbit antiserum against mouse heavy chains and labelled to FITC. (Becton and Dickinson, Mountain View, California, USA) The conjugates were used in a 50-fold working dilution. None of the conjugates reacted directly with the adherent treponemes. No cross-reactivity was observed between the IgG and IgM conjugates as demonstrated by the negative reactions of the IgG conjugate on adherent treponemes incubated with the IgM(SII) fraction and vice versa.

The immunofluorescence studies were performed on adherent treponemes on the cover-slips which were placed in petridishes. The cover-slips were overlaid with the appropriate dilutions of the sera, serum fractions or monoclonal antibody and incubated for $30 \mathrm{~min}$. They were then rinsed with PBS, and subsequently incubated for $30 \mathrm{~min}$ with the appropriate conjugate. They were rinsed again and placed upside down on microscope slides. The preparations were sealed with nail polish and read immediately. In the experiments performed to inhibit the fluorescence produced by the $\operatorname{IgG}$ (SII) and the $\operatorname{IgM}(\mathrm{SII})$ fractions by serum, the incubations with the antibody containing serum fractions were either preceded or followed by an incubation by one of the control sera for $30 \mathrm{~min}$.

The slides were examined on a Leitz Orthoplan binocular microscope in alternating darkfield and UV illumination. The microscopic equipment and the evaluation of the results read under UV illumination were as described previously. ${ }^{17}$ A minimum of 200 treponemes per slide were examined and the treponemes showing at least a $1+$ reaction were considered as positive. The number of positive treponemes were expressed for each slide as a percentage of the total number of treponemes observed.

\section{Results}

Both the fibroblast- and the FN-adhering treponemes on all occasions showed no reaction with the anti-axial filament MoAb CC9. However, using airdried or acetone treated preparations all treponemes showed a strong positive reaction with this antibody. The interrupted filamentous pattern of fluorescence was compatible with the structure of the axial filaments twisting around the treponemes. No differences were observed between the fresh and aged treponemes.

The sero-positive primary and the secondary syphilis sera when incubated with the appropriate conjugate, consistently showed no fluorescence for IgG as well as for IgM with the fibroblast- or FN adherent treponemes. This was true for the fresh and the aged treponemes from the twelve suspensions tested for IgG, and the six suspensions tested for IgM. Only occasionally a very weak fluorescence was observed indicating that some immunoglobulins might have been present. This was especially apparent for IgM anbtibodies. Air-dried or acetone treated preparations of adherent treponemes showed a strong positive fluorescence for IgG after incubation with the syphilitic sera and conjugate. However, the treponemes showed only a weak fluorescence after incubation of these preparations with the sera and anti-IgM conjugate.

The results with the immunoglobulin-containing serum fractions are shown in table 1 . When the IgG(SII) fraction was used, a mean of $14.5 \%$ of the fresh treponemes adhering to the fibroblasts showed a positive IgG fluorescence of a $1+$ to $2+$ intensity. This percentage increased to a mean of $32.1 \%$ when aged treponemes were used. The remaining treponemes were completely negative. When the IgM(SII) fraction was used, a mean of $43.2 \%$ of the fibroblast adhering fresh treponemes showed a bright, strongly positive fluorescence, the remaining treponemes being completely invisible. Using the aged treponemes this increased to a mean of $87 \cdot 3 \%$. It can be seen in table 1 that a greater percentage of the treponemes adhering to the fibroblasts than that adhering to the FN layers showed a positive fluorescence with the IgG(SII) and IgM(SII) fractions. No non-specific binding of immunoglobulins was detected since the controls with $\operatorname{IgG}(\mathrm{C})$ and $\operatorname{IgM}(\mathrm{C})$, that were run in parallel, were consistently negative.

When the treponemes were pre-treated with acetone or air-dried, they all displayed a bright, stongly positive fluorescence with the IgG(SII) fraction and conjugate. However, with the IgM(SII) fraction only a very weak fluorescence was observed.

The absence of fluorescence with the whole syphilitic sera on the one hand and the (partially) positive fluorescence with the antibody containing fractions from these sera on the other, prompted us to investigate whether whole sera interfered with the IgM and IgG fluorescence. Table 2 shows the results of the experiments using four different suspensions of treponemes adhering to fibroblasts. The incuba-

Table 1 Percentages of fresh and aged treponemes, which adhere to fibroblast or fibronectin layers, and which show a positive reaction with IgG or IgM containing serum fractions, isolated from sera of patients with secondary syphilis

\begin{tabular}{|c|c|c|c|c|c|c|}
\hline & \multicolumn{3}{|c|}{ Fibroblasts } & \multicolumn{3}{|c|}{ Fibronectin } \\
\hline & $n$ & Fresh & Aged & $n$ & Fresh & Aged \\
\hline $\begin{array}{l}\text { IgG } \\
\text { IgM }\end{array}$ & $\begin{array}{r}12 \\
6\end{array}$ & $\begin{array}{l}14 \cdot 5(8 \cdot 1) \\
43 \cdot 2(15 \cdot 4)\end{array}$ & $\begin{array}{l}32.1(11.7) \\
87.3(7.9)\end{array}$ & $\begin{array}{r}12 \\
6\end{array}$ & $\begin{array}{l}1.9(3.0) \\
2 \cdot 2(1.6)\end{array}$ & $\begin{array}{l}13 \cdot 2(7 \cdot 6) \\
52 \cdot 2(2 \cdot 6)\end{array}$ \\
\hline
\end{tabular}

SD in parenthesis.

$n$ indicates the number of different suspensions of treponemes tested. 
Table 2 Means and standard deviations of percentages of four different suspensions of fibroblast-adhering treponemas which show a positive reaction with IgG or IgM containing serum fractions isolated from sera of patients with secondary syphilis

\begin{tabular}{|c|c|c|c|c|c|}
\hline \multicolumn{4}{|c|}{ Sequential incubations } & \multirow{2}{*}{$\begin{array}{l}\text { Fresh } \\
16 \cdot 0(9 \cdot 9) \\
8 \cdot 8(5 \cdot 6) \\
0 \\
0\end{array}$} & \multirow{2}{*}{$\begin{array}{l}\text { Aged } \\
34 \cdot 3(10 \cdot 0) \\
36 \cdot 8(12 \cdot 5) \\
0 \\
0\end{array}$} \\
\hline $\begin{array}{l}\text { IgG(SII) } \\
\text { c. serum } \\
\text { IgG(SII) } \\
\text { IgG(SII) }\end{array}$ & $\begin{array}{l}\text { aIgG } \\
\text { IgG(SII) } \\
\text { c. serum } \\
\text { c. serum }\end{array}$ & $\begin{array}{l}\text { aIgG } \\
\text { aIgG } \\
\text { IgG(SII) }\end{array}$ & algG & & \\
\hline $\begin{array}{l}\text { IgM(SII) } \\
\text { c. serum } \\
\text { IgM(SII) } \\
\text { IgM(SII) }\end{array}$ & $\begin{array}{l}\text { aIgM } \\
\text { IgM(SII) } \\
\text { c. serum } \\
\text { c. serum }\end{array}$ & $\begin{array}{l}\operatorname{aIgM} \\
\operatorname{aIgM} \\
\operatorname{IgM}(S I I)\end{array}$ & algM & $\begin{array}{l}32.3(6.0) \\
0.8(1.0) \\
0 \\
0\end{array}$ & $\begin{array}{l}97 \cdot 8(4 \cdot 5) \\
5 \cdot 3(4 \cdot 5) \\
0 \\
0\end{array}$ \\
\hline
\end{tabular}

Abbreviations:

aIgG and IgM indicate the conjugate used.

c. serum indicates control serum.

tion of fresh, fibroblast-adhering treponemes with the control sera before the incubation with the IgG(SII) fraction diminished the percentage of fluorescence-positive treponemes. This procedure had no influence when aged treponemes were used. The IgM fluorescence of the fresh as well as the aged treponemes was almost completely abolished by this treatment. When the incubation of the adherent treponemes with the $\operatorname{IgG}(\mathrm{SII})$ or $\operatorname{IgM}(\mathrm{SII})$ fractions was followed by an incubation with a control serum, the fluorescence produced by both antibody containing fractions was completely inhibited. Repeated incubations with each of these antibody-containing fractions, followed by the appropriate conjugate resulted in an absence of fluoresence-positive treponemes. This result demonstrated that the access to the treponemal outer membrane was completely obstructed by the components of the control sera.

Table 3 Detection of IgG and IgM class antibodies and the third complement component (C3) on fibroblast-adhering treponemas after various incubations. The means and standard deviations of percentages of three experiments with different suspensions are shown

\begin{tabular}{|c|c|c|c|c|}
\hline \multirow[b]{2}{*}{ Sequential incubations ${ }^{\star}$} & \multicolumn{2}{|l|}{ Ig } & \multicolumn{2}{|l|}{ C3 } \\
\hline & Fresh & Aged & Fresh & Aged \\
\hline $\begin{array}{l}\text { c. serum } \\
\text { SI }{ }^{+} \text {serum } \\
\text { SII serum } \\
\text { Clq def serum }\end{array}$ & $\begin{array}{c}\text { n.d. } \\
\text { of } \\
\text { of } \\
\text { n.d. }\end{array}$ & $\begin{array}{c}\text { n.d. } \\
0 \\
0 \\
\text { n.d. }\end{array}$ & $\begin{array}{r}100 \\
100 \\
100 \\
0\end{array}$ & $\begin{array}{r}100 \\
100 \\
100 \\
0\end{array}$ \\
\hline $\begin{array}{l}\text { IgG(SII) } \\
\text { IgG(SII)/c. serum } \\
\text { IgG(SII)/c. serum } \ddagger \\
\text { IgG(SII)/C3 def serum }\end{array}$ & $\begin{array}{l}11 \cdot 0(8 \cdot 2) \\
0 \\
3 \cdot 0(2 \cdot 6) \\
3 \cdot 7(3 \cdot 2)\end{array}$ & $\begin{array}{l}33 \cdot 6(6 \cdot 8) \\
0 \\
6 \cdot 3(3 \cdot 2) \\
9 \cdot 7(4 \cdot 5)\end{array}$ & $\begin{array}{r}\text { n.d. } \\
100 \\
0 \\
0\end{array}$ & $\begin{array}{r}\text { n.d. } \\
100 \\
0 \\
0\end{array}$ \\
\hline $\begin{array}{l}\operatorname{IgM}(\text { SII }) \\
\operatorname{IgM(SII)/c.~serum~} \\
\mathrm{IgM(SII)/c.} \mathrm{serum} \ddagger \\
\text { IgM(SII)/C3 def serum }\end{array}$ & $\begin{array}{l}26 \cdot 7(5 \cdot 5) \\
0 \\
15 \cdot 7(7 \cdot 6) \\
19 \cdot 0(7 \cdot 2)\end{array}$ & $\begin{array}{l}87 \cdot 7(5 \cdot 9) \\
0 \\
18 \cdot 7(9 \cdot 5) \\
48 \cdot 7(9 \cdot 0)\end{array}$ & $\begin{array}{r}\text { n.d. } \\
100 \\
0 \\
0\end{array}$ & $\begin{array}{r}\text { n.d. } \\
100 \\
0 \\
0\end{array}$ \\
\hline
\end{tabular}

*These incubations were followed by one with the appropriate conjugate.

tapplies to IgG as well as IgM class antibodies in the five sera of the category mentioned.

findicates that the serum was heat inactivated.

n.d. $=$ not done.
As shown in table 3, the third complement component (C3) was invariably present on all adherent treponemes when they were incubated with syphilitic sera or control sera alone. After incubation with the Clq deficient serum no C3 was detected on the treponemal surface. This excludes a spontaneous absorption of native $\mathrm{C} 3$ or an activation of complement via the alternative pathway by the adherent treponemes as the cause of the deposition of C3. After incubations with IgG(SII) or IgM(SII) followed by one of the control sera C3 was also present on all treponemes. The use of heat-inactivated sera in this procedure prevented the deposition of $\mathrm{C} 3$ on the treponemes. Nevertheless, these incubations inhibited partially the IgG- and IgM fluorescence as compared with incubations with these antibody-containing fractions alone. This indicated, that besides C3, other serumcomponents contributed to the inhibition of fluorescence.

\section{Discussion}

The negative results of MoAb CC9 with native adherent treponemes show that both fresh and aged treponemes possess an intact outer membrane, which prevents the access of antibodies to the antigens located underneath this membrane. However, the positive results with this MoAb on adherent treponemes after treatment with acetone or air-drying demonstrated that these treatments resulted in a modification of the outer surface of the treponemes which enabled the antibodies to combine with their epitopes on intracellularly located antigens. This demonstrates that untreated, adherent treponemes are a suitable substrate for studying the interactions of antibodies with the outer membrane without the interference of antibodies to intracellularly located antigens.

We have shown that a large part of the fresh treponemes adhering to the fibroblasts or FN did not stain with the IgG(SII) and IgM(SII) fractions. This indicated that the state of the outer surface of these treponemes prevents the binding of antibodies. When aged treponemes were used, approximately $10 \%$ of the fibroblast-adhering treponemes were negative for IgM. Aged treponemes adhering to FNlayers showed a mean of $50 \%$ IgM negative treponemes. The percentages of the aged treponemes that were IgG negative were $68 \%$ for fibroblast-adhering treponemes and $87 \%$ for $\mathrm{FN}$-adhering treponemes. The increase in the percentages of staining treponemes on aging is compatible with a change in the state of the outer surface of the treponemes. This may concern changes in the outer membrane itself perhaps due to insufficient in vitro metabolic capacity of the treponemes to maintain the inert character of the outer membrane or due to a loss of an extracellular cover of the outer membrane.

Using the IgG(SII) fraction consistently lower 
percentages of fluorescence-positive treponemes were detected than using the IgM(SII) fraction. This did not change when a four-fold concentrated IgG(SII) fraction was used. We have previously shown that during the SII stage the IgG production reached its maximum. ${ }^{1719}$ Moreover, this fraction produced strong positive reactions on acetone-treated of airdried preparations. The differences between the staining with both serum fractions might be explained by the multivalency of the IgM antibodies, which enable them to bridge larger distances between epitopes than the IgG antibodies. Alternatively, the differences might be explained by the assumption that the production of IgG antibodies to the outer membrane components is less extensive than the production of IgM antibodies. Moreover, it is not known whether the lower number of IgG positive treponemes are due to the inaccessibility of the relevant antigens on the membrane or are due to the absence of IgG antibodies to some outer membrane components or epitopes. A suppressed IgG response to the $\mathrm{T}$-cell dependent, unrelated sheep red blood cell antigen during a syphilitic infection in rabbits has been reported. ${ }^{2021}$ Further studies should differentiate between these possibilities.

The differences between fibroblast and $\mathrm{FN}$ layers with respect to the percentages of positively staining, adherent, treponemes might be related to the larger diversity of ligands available on the fibroblasts than on FN. As demonstrated by Fitzgerald et $a l^{2}$ treponemes adhere not only to FN, but also to collagen type I and IV, laminin and hyaluronic acid. Exposed sites on the outer membrane of the treponemes may be responsible for the adherence to these substances and at the same time for the larger percentage of positively staining treponemes.

The negative results for IgG and IgM fluorescence with the syphilitic sera could be reproduced by using sequential incubations with the IgG(SII) or IgM(SII) fractions and control sera. This was invariably accompanied by the presence of a layer of $\mathrm{C} 3$ around all the treponemes. However, the use of either heatinactivated sera or a $\mathrm{C} 3$ deficient serum in the second incubation after the treponemes had been coated with $\operatorname{IgG}(\mathrm{SII})$ or IgM(SII) did not result in a C3 layer. This restored only partially the possibility to detect the antibodies on the treponemal surface and shows that serum proteins other than $\mathrm{C} 3$ can contribute to the inability to detect antibodies on the treponemal surface. The most likely explanation is that antibodies become buried in a layer of serum proteins around the treponemes rather than a loss of antibodies, since repeated incubations with antibodies and conjugate (compare lines 4 and 8 in table 2) were not able to restore the fluorescence.

Interestingly, the incubation with the control sera alone also resulted in a C3 layer around all the treponemes present. A C3 layer was absent when the treponemes were incubated with a $\mathrm{Clq}$ deficient serum. This excludes a C3 deposition via the alternative pathway as well as a spontaneous binding of $\mathrm{C} 3$ to the treponemal surface and favours the classical pathway of complement activation as a cause of the C3 deposition. One possible explanation for the C3 deposition from the control sera is that antibodies may be present on the treponemal surface. These antibodies must have been derived from the rabbits from which the treponemes had been isolated. However, our attempts to detect these antibodies by means of fluorescence failed. An explanation might be that they are buried in an extracellular layer and that other techniques are needed for their detection. Indeed, several authors have shown that C3, IgG and IgM were among the host serum proteins present on the treponemal surface. ${ }^{123}$ However, it remains puzzling to us how these antibodies remained undetected by our fluorescence technique while at the same time, they are able to activate complement. An alternative explanation for the $\mathrm{C} 3$ deposition is that treponemes possess an intrinsic mechanism of complement activation. However, no experimental evidence for this possibility is as yet available.

Further investigations will require purified treponemes that are free of host components in order to elucidate the manner in which the various host components contribute in the formation of an extracellular layer, thus allowing the treponemes to escape the combined action of antibodies and complement.

1 Baker-Zander SA, Hook EW III, Bonin P, Handsfield HH, Lukehart SA. Antigens of Treponema pallidum recognised by IgG and IgM antibodies during syphilis in humans. I Infect Dis 1985;151:264-72.

2 Hanff PA, Fehninger TE, Miller JN, Lovett MA. Humoral immune response in human syphilis to polypeptides of Treponema pallidum. J Immunol 1982;129:1287-91.

3 Moskophidis M, Müller F. Molecular analysis of immunoglobulins $M$ and $G$ immune response to protein antigens of Treponema pallidum in human syphilis. Infect Immun 1984;43:127-32.

4 van Eijk RVW, van Embden JDA. Molecular characterisation of Treponema pallidum proteins responsible for the human immune response to syphilis. Antonie van Leeuwenhoek. J Microbiol 1982;48:486-7.

5 Hanff PA, Bishop NH, Miller JN, Lovett MA. Humoral immune response in experimental syphilis to polypeptides of Treponema pallidum. J Immunol 1983;131:1973-7.

6 Stamm LV, Bassford PJ. Cellular and extracellular protein antigens of Treponema pallidum synthesised during in vitro incubation of freshly extracted organisms. Infect Immun 1985;47:799-808.

7 Alderete JF, Baseman JB. Surface characterisation of virulent Treponema pallidum. Infect Immun 1980;30:814-23.

8 Moskophidis M, Müller F. Molecular characterisation of glycoprotein antigens on surface of Treponema pallidum: Comparison with nonpathogenic Treponema phagedenis biotype Reiter. Infect Immun 1984;46:867-9.

9 Christiansen S. Hypothesis: Protective layer covering pathogenic treponemata. Lancet 1963;i:423-5.

10 Fitzgerald TJ, Johnson RC, Wolff ET. Mucopolysaccharide material resulting from the interaction of Treponema pallidum (Nichols strain) with cultured mammalian cells. Infect Immun 1978;22:575-84.

11 Zeigler JA, Jones AM, Jones RH, Kubica KM. Demonstration of extra-cellular material on the surface of pathogenic Treponema pallidum cells. Br J Venereal Dis 1976;52:1-8.

12 Alderete JF, Baseman JB. Surface associated host protein on 
virulent Treponema pallidum. Infect Immun 1979;26:1048-56.

13 Marchitto KS, Kindt TJ, Norgard MV. Monoclonal antibodies directed against major histocompatibility complex antigens bind to the surface of Treponema pallidum isolated from rabbits and humans. Cell Immunol 1986;101:633-42.

14 van der Sluis JJ, Onvlee PC, Kothe FCHA, Vuzevski VD, Aelbers GMN, Menke HE. Transfusion syphilis, survival of Treponema pallidum in stored donor blood. 1. Report of an orientating study. Vox Sang 1984;47:197-204.

15 Fieldsteel AH, Moeckli RA. Cultivation of Treponema pallidum in tissue culture. Infect Immun 1981;32:908-15.

16 van der Sluis JJ, Koehorst JAM, Boer AM. Factors that inhibit the adherence of Treponema pallidum (Nichols strain) to a human fibroblastic cell-line: development in serum of patients with syphilis. Genitourin Med 1987;63:71-6.

17 van der Sluis JJ, van Reede EC, Boer AM. Immunoglobulin G subclasses of fluorescent anti-Treponema pallidum antibodies: Evidence for sequential development of specific anti- $T$ pallidum immunoglobulin $\mathbf{G}$ responses in patients with early syphilis. J Clin Microbiol 1986;24:418-23.

18 Roord JJ, Daha M, Kuis W, Verbrugh HA, Verhoef J, Zegers BJM, Stoop JW. Inherited deficiency of the third component of complement associated with recurrent pyogenic infections, circulating immune complexes, and vasculitis in a Dutch family. Pediatrics 1983;171:81-7.

19 van der Sluis JJ, Boer AM. Uneven distribution of anti-treponema antibody activity in differing immunoglobulin $G$ fractions from patients with early syphilis. Infect Immun 1980;29:837-41.

20 Baughn RE, Musher DM. Altered immune responsiveness associated with experimental syphilis in the rabbit: Elevated IgM and depressed IgG responses to sheep erythrocytes. $J$ Immunol 1978;120:1691-5.

21 Baughn RE, Musher DM. Aberrant secondary antibody responses to sheep erythrocytes in rabbits with experimental syphilis. Infect Immun 1979;25:133-8.

22 Fitzgerald TJ, Repesh LA, Blanco DR, Miller JN. Attachement of Treponema pallidum to fibronectin, laminin, collagen IV and collagen $I$, and blockage of attachment by immune rabbit IgG. Br J Venereal Disease 1984;60:357-63.

23 Baughn RE. Antibody-independent interactions of fibronectin, C19 and human neutrophils with Treponema pallidum. Infect Immun 1986;54:456-64.

Accepted 23 January 1990 